\title{
ACUTE RENAL FAILURE DUE TO ABDOMINAL COMPARTMENT SYNDROME: REPORT ON FOUR CASES AND LITERATURE REVIEW
}

\author{
Roberto de Cleva, Fabiano Pinheiro da Silva, Bruno Zilberstein and \\ David J B Machado
}

CLEVA R de et al. - Acute renal failure due to abdominal compartment syndrome: report on four cases and literature review. Rev. Hosp. Clín. Fac. Med. S. Paulo 56(4):123-130, 2001.

We report on 4 cases of abdominal compartment syndrome complicated by acute renal failure that were promptly reversed by different abdominal decompression methods. Case 1: A 57-year-old obese woman in the post-operative period after giant incisional hernia correction with an intra-abdominal pressure of $24 \mathrm{~mm} \mathrm{Hg}$. She was sedated and curarized, and the intra-abdominal pressure fell to $15 \mathrm{~mm} \mathrm{Hg}$. Case 2: A 73-year-old woman with acute inflammatory abdomen was undergoing exploratory laparotomy when a hypertensive pneumoperitoneum was noticed. During the surgery, enhancement of urinary output was observed. Case 3: An 18year-old man who underwent hepatectomy and developed coagulopathy and hepatic bleeding that required abdominal packing, developed oliguria with a transvesical intra-abdominal pressure of $22 \mathrm{~mm} \mathrm{Hg}$. During reoperation, the compresses were removed with a prompt improvement in urinary flow. Case 4: A 46-year-old man with hepatic cirrhosis was admitted after incisional hernia repair with intra-abdominal pressure of $16 \mathrm{~mm} \mathrm{Hg}$. After paracentesis, the intra-abdominal pressure fell to $11 \mathrm{~mm} \mathrm{Hg}$.

DESCRIPTORS: Acute renal failure. Abdominal compartment syndrome.

Wendt was the first to report in 1876 the reduction of urinary flow associated with intra-abdominal hypertension (IAH) ${ }^{13}$. Increased intra-abdominal pressure (IAP) during laparoscopic surgery or after other surgical procedures has been associated with oliguria and anuria ${ }^{1-8}$. The basic sciences and clinical observations have confirmed the effects of elevated IAP on multiple organ systems ${ }^{9-12}$. The abdomen is a closed space, and it has been known since the beginning of this century that high IAP may be detrimental; for example, the compartment syndromes in the extremities observed after trauma or vascular surgery ${ }^{3}$. A compartment syndrome is defined as a condition in which a confined space adversely affects the circulation and threatens the function and viability of the tissues. The term abdominal compartment syndrome (ACS) was first used by Kron et al. ${ }^{8}$ in the early 1980 s to describe the pathophysiology resulting from IAH secondary to surgery for aortic aneurysm. Intra-abdominal hypertension develops when intra-abdominal pressure is above $10 \mathrm{~mm} \mathrm{Hg}$, and it can cause organ dysfunction ${ }^{13}$. Abdominal pressures higher than 15 to $25 \mathrm{~mm} \mathrm{Hg}$ have been shown to cause: increased intrathoracic pressures; decreased cardiac output and stroke vol-

From the Department of Gastroenterology (Surgical ICU), Hospital das Clínicas, Faculty of Medicine, University of São Paulo. ume; increased intracranial pressure; decreased flow in the celiac, superior mesenteric, and renal arteries; decreased small bowel mucosal tension; and predisposition for bacterial translocation $^{13}$.

Abdominal compartment syndrome is diagnosed when IAP causes intraand extra-abdominal organ dysfunction and failure. A useful definition of ACS requires an IAP greater than $20 \mathrm{~mm} \mathrm{Hg}$ complicated by at least one of the following: peak airway pressure greater than $45 \mathrm{~cm} \mathrm{H}_{2} \mathrm{O}$, oxygen delivery index less than $600 \mathrm{~mL} 0_{2} / \mathrm{min} / \mathrm{m}^{2}$, urine output less than $0.5 \mathrm{~mL} / \mathrm{kg} / \mathrm{h}$, or hemodynamic instability needing catecholamines ${ }^{13,14}$. Abdominal decompression must result in clinical improvement. 
The most recent work by Sugrue et al. ${ }^{14}$ and Ivatury et al. ${ }^{15}$ revised the classic definition of ACS to include isolated impairment of gut perfusion, because it adversely affects outcome independent of other organ dysfunction.

We report 4 cases of ACS associated with acute renal failure (ARF).

\section{CASE REPORTS}

Case 1: A 57-year-old obese woman was admitted in the post-operative period after giant incisional hernia correction. Her body mass index was $42 \mathrm{~kg} / \mathrm{m}^{2}$ and serum creatinine was $0.6 \mathrm{mg} / \mathrm{dL}$ in the pre-operative period. She developed abdominal distension and oliguria $(190 \mathrm{~mL}$ in the first 12 hours) after surgery. After 20 hours she had an arterial blood pressure (ABP) of 120/70 mm $\mathrm{Hg}$ and a central venous pressure (CVP) of $19 \mathrm{~cm} \mathrm{H}_{2} \mathrm{O}$, but maintained oliguria (urinary output $15 \mathrm{~mL} / \mathrm{hr}$ ), and serum creatinine rose to $1.8 \mathrm{mg} / \mathrm{dL}$. A challenge of intravenous furosemide failed. At this time, intraabdominal pressure (IAP) was measured using the transvesical technique, and it was $24 \mathrm{~mm} \mathrm{Hg}$. Then the patient was sedated and curarized; the IAP fell to $15 \mathrm{~mm} \mathrm{Hg}$, she presented a urinary flow of $640 \mathrm{mLin} 7$ hours, and serum creatinine dropped to $1.3 \mathrm{mg} / \mathrm{dL}$.

Case 2: A 73-year-old woman was admitted due to acute inflammatory abdomen. She presented significant abdominal distension, anuria, and serum urea and creatinine elevations (106 $\mathrm{mg} / \mathrm{dL}$ and $3.5 \mathrm{mg} / \mathrm{dL}$, respectively). After optimization of filling pressures, she underwent exploratory laparotomy during which a hypertensive pneumoperitoneum was noticed. During the surgery, enhancement of urinary output was observed.

Case 3: An 18-year-old man underwent hepatectomy for a giant fibrolamellar hepatic carcinoma. In the operating room, he developed coagulopathy and hepatic bleeding. Abdominal packing with surgical compresses was the treatment of choice. In the post-operative follow-up, the patient developed oliguria and worsening of renal function. The transvesical IAP measurement was $22 \mathrm{~mm} \mathrm{Hg}$. During reoperation, when the compresses were removed there was a prompt improvement in urinary flow.

Case 4: A 46-year-old man with portal hypertension secondary to hepatic cirrhosis was admitted after incisional hernia repair. He presented abdominal distension, oliguria, and respiratory distress. The transvesical IAP was $16 \mathrm{~mm} \mathrm{Hg}$, and serum creatinine was $5.0 \mathrm{mg} / \mathrm{dL}$. After paracentesis, adequate volume replacement, and intravenous furosemide, he presented $580 \mathrm{~mL}$ of diuresis in 12 hours, the IAP fell to $11 \mathrm{~mm} \mathrm{Hg}$, and serum creatinine fell to $3.9 \mathrm{mg} / \mathrm{dL}$.

\section{PATHOGENESIS}

There are many different causes of acutely elevated IAP. Abdominal compartment syndrome develops with acute and rapid elevation in IAP. Chronic increases in intra-abdominal volume, such as in morbidly obese patients, lead to a slower increase in IAP as the abdominal wall accommodates and becomes more compliant with time-the so-called "stress-relation" phenomenon ${ }^{16}$. With this gradual increase, the organ systems are able to compensate for the changes in IAP, and the acute deterioration seen with ACS does not occur in these patients. Elevated IAP in these individuals is not benign. The morbidity that occurs in these conditions (central obesity) is at least in part attributable to the chronically elevated $\mathrm{IAP}^{17,18}$.

Abdominal compartment syndrome can develop in both nonsurgical and surgical patients. Increases in retroperitoneal volume from pancreatitis, hem- orrhage, or edema from pelvic trauma or aortic surgery can lead to ACS ${ }^{19-22}$. Increased intraperitoneal volume is the most common cause of elevated IAP. These include intraperitoneal hemorrhage, bowel distension, mesenteric venous obstruction, abdominal packs, tense ascites, peritonitis, and tumor ${ }^{22-30}$. Extrinsic compressions of the abdomen caused by burn eschars, tight abdominal closures, and repair of large incisional hernias can also lead to increases in IAP $^{31-33}$. In most critically ill patients, IAP leading to ACS is multifactorial. Massive volume resuscitation can lead to increased IAP in patients in the postoperative period or with sepsis due to the effects of capillary leakage and ischemia-reperfusion injury ${ }^{34}$. The circulatory effects of increased IAP, combined with extracellular edema, may lead to abdominal wall edema and ischemia, reducing abdominal compliance and further accentuating the IAP increases ${ }^{35}$. In critically ill patients, these factors are additive, aggravating multiple organ failure.

\section{MEASUREMENT OF INTRA- ABDOMINAL PRESSURE}

There are many methods for measuring IAP. Direct measurement, except in laparoscopic procedures, is not used, since indirect methods, particularly the transvesical method, are reliable and relatively noninvasive. The transvesical method is considered the "gold standard" for indirect clinical measurement of IAP.

The wall of the urinary bladder behaves as a passive diaphragm when the bladder volume is between 50 and $100 \mathrm{~mL}$. Pressure measurements recorded simultaneously through a peritoneal dialysis catheter and a transurethral urinary bladder catheter were equal during several infusions of peritoneal dialysis solution for pressures of 5 and $50 \mathrm{~mm} \mathrm{Hg}^{7}$. The reference point, 
considered the zero point, is the top of the symphysis pubis with the patient supine. Fifty to $100 \mathrm{~mL}$ of saline is injected into the empty bladder through the indwelling Folley catheter. The drainage bag is cross-clamped just distal to the culture aspiration port, and a 16-gauge needle is inserted through the aspiration port and connected to a pressure transducer? This technique has been validated in animal models showing a high degree of correlation with directly measured IAP ${ }^{36,37,38}$. A simplification of this method can be done by elevating the closed urine bag collecting system above the patient's symphysis pubis. Urine will flow back into the bladder through the urinary catheter until equilibrium is reached. The column height is measured in units of $\mathrm{cm}$ of $\mathrm{H}_{2} \mathrm{O}$ and is considered equivalent to the IAP ${ }^{8}$.

Two of our patients had urinary bladder IAP measurements that established their diagnosis and dictated treatment.

Compared with bladder pressure measurements, clinical abdominal assessment has poor sensitivity and accuracy for elevated IAP ${ }^{39}$.

A femoral vein catheter can be used to measure pressure within the inferior vena cava, which correlates well with the direct measurement. Validation studies in humans have never been done, probably because they are impractical, invasive, and carry significant risk $^{36}$.

Another indirect method that has been described for measuring IAP uses the intrarectal pressure. In this method, the intrarectal pressure is obtained by introduction of a $12 \mathrm{~F}$ balloon-tipped catheter connected to a pressure transducer into the rectum $8-10 \mathrm{~cm}$ from the anal verge. The investigators found no significant differences between the intrarectal pressure and the direct measurement of IAP $^{37}$.

The esophagus and the stomach have also been used for IAP measure- ment ${ }^{40,41}$. The intragastric pressure also has good correlation with the IAP. Intragastric pressure can be determined by infusing $50-100 \mathrm{~mL}$ of water into the gastric cavity through a nasogastric tube. The proximal end of the open tube is held perpendicular to the floor. The distance of the water level to the midaxillary line is taken as the IAP in $\mathrm{cm} \mathrm{H}_{2} 0$. This measurement has an acceptable correlation to urinary bladder pressure $^{42}$. The gastric tonometer catheter may also be used ${ }^{43}$. Intragastric measurement is the method of choice in patients when there are contraindications or when utilization of the bladder is impossible. This measurement is easy to perform. Additionally, it does not interfere with the urinary output measurement, and it promotes continuous monitoring of abdominal pressure. However, intragastric measurement is more expensive and less accepted than the urinary bladder method in clinical practice.

Although IAP can physiologically reach elevated values (cough, Valsalva maneuver, weight lifting, etc.), these values can not be tolerated for long periods, and during most of the day, its value is kept around zero. Values above $10 \mathrm{~mm} \mathrm{Hg}$ are considered abnormal.

Intra-abdominal hypertension must be considered in high-risk patients presenting abdominal distension, respira- tory distress, worsening of clinical evolution, or acute renal insufficiency (Table 1).

Intra-abdominal pressure can be graded as: Grade I; between 10 and 20 $\mathrm{mm} \mathrm{Hg}$; Grade II, between 21 and $35 \mathrm{~mm} \mathrm{Hg}$; and Grade III, above $35 \mathrm{~mm}$ $\mathrm{Hg}^{4}$. Other grading systems have been proposed $^{5}$. Abdominal compartment syndrome is invariably manifested when the IAP is above $20 \mathrm{~mm} \mathrm{Hg}$. Symptomatic IAH Grade III must be treated with immediate surgical decompression; it is unnecessary and dangerous to prolong clinical treatment or diagnostic investigation ${ }^{6}$.

\section{PATHOPHYSIOLOGY OF ELEVATED IAP}

\section{Renal derangements}

Oliguria progressing to anuria and prerenal azotemia unresponsive to volume expansion characterize the renal dysfunction of $\mathrm{ACS}^{22,30,44,45}$. Deterioration of renal function affects the prognosis directly, increasing the importance of a rapid diagnosis and treatment.

Many mechanisms have been proposed to explain the effects of IAP on renal function. Intra-abdominal pressure above $15 \mathrm{~mm} \mathrm{Hg}$ is related to de-

Table 1- Causes of Intra-abdominal Hypertension.

Causes of Intra-abdominal Hypertension

Peritoneal tissue edema, secondary to trauma or peritonitis

Fluid overload in septic or hypovolemic shock

Retroperitoneal hematoma secondary to trauma or aortic rupture

Tissue injury secondary to surgical procedure

Reperfusion injury after bowel ischemia of any cause

Retroperitoneal or mesenteric inflammation secondary to acute pancreatitis

Ileus or bowel obstruction

Intra-abdominal tumors

Abdominal packing for hemorrhage control

Abdominal closure under tension

Ascites and other forms of intra-abdominal fluid accumulation 
velopment of oliguria, while IAP above $30 \mathrm{~mm} \mathrm{Hg}$ is related to anuria ${ }^{46}$. This can occur even during a laparoscopic surgery ${ }^{44,47}$. Amelioration of renal function after abdominal decompression has been demonstrated in many studies ${ }^{19,20,44,47,48}$, and dopamine administration does not appear to have a protective effect ${ }^{44}$.

Impairment of venous return by inferior cava vein compression cannot alone completely explain the manifestations of renal function deterioration, since optimization of cardiac output and filling pressures do not reverse this complication ${ }^{49}$.

Renal derangements involve effective renal blood flow and reduction of the glomerular filtration rate, water reabsorption, and increase in renal vein pressure. These effects have been attributed to increases in total renal vascular resistance due to direct compression of the renal vein and parenchyma $^{19}$. Renal derangements may also be due to corticomedullary shunting of renal plasma flow, reducing effective renal plasma flow.

An increase in antidiuretic hormone production was demonstrated in dogs with an IAP of $80 \mathrm{~mm} \mathrm{Hg}^{51}$. Moreover, increased circulation levels of renin and aldosterone can be seen secondary to renal and systemic hemodynamic changes, which further increases renal vascular resistance and produces sodium and water retention. Renin and aldosterone levels decrease partially with volume expansion and further with abdominal decompression. Elevated IAP does not seem to have a significant effect on the aorta and renal artery flow or on ureter patency ${ }^{51,52}$.

\section{Cardiovascular derangements}

Elevation in IAP greater than 20 $\mathrm{mm} \mathrm{Hg}$ leads to a reduction in cardiac output $(\mathrm{CO})^{38,52,53,54,55}$. The diminished $\mathrm{CO}$ results from direct compression of the inferior vena cava decreasing venous flow, as well as from an increased thoracic pressure, which decreases both inferior and superior vena caval flow. The increased thoracic pressure also results in cardiac compression with decreased ventricular end-diastolic volume. Intra-abdominal hypertension also leads to an increased systemic afterload. All of these lead to a reduced stroke volume with a compensatory increase in heart rate. Diaphragmatic elevation markedly elevates pleural pressure in animal models ${ }^{56}$. This increase is transmitted to the heart and central veins, leading to spuriously elevated central venous pressure, pulmonary artery pressure, and pulmonary wedge pressure combined with a reduced CO. If the measured pleural pressure is subtracted, the true pressures may actually decrease with IAH. If this is not taken in consideration, the hemodynamic profile can be confused with biventricular failure ${ }^{38}$.

\section{Abdominal abnormalities}

Intra-abdominal hypertension reduces both mesenteric arterial and portal venous flow ${ }^{57}$. Diebel et al found that while reductions in mesenteric and intestinal mucosal blood flow occurred at an IAP of $20 \mathrm{~mm} \mathrm{Hg}$, portal flow became compromised at only $10 \mathrm{~mm}$ $\mathrm{Hg}^{12}$. An IAP greater than $20 \mathrm{~mm} \mathrm{Hg}$ impairs intestinal perfusion at the mucosal and submucosal levels, leading to anaerobic cell metabolism and metabolic acidosis ${ }^{58,59}$. Gastric tonometry may be a sensitive clinical indicator of gut ischemia in $\mathrm{ACS}^{60}$. Recent evidence suggest that elevations in IAP greater than $10 \mathrm{~mm} \mathrm{Hg}$ are associated with sepsis, multiple organ failure, and mortality $^{61,62}$.

\section{Pulmonary disfunction}

Respiratory failure due to an acute elevation in IAP is characterized by high inspiratory pressures, hypoxia, and hypercarbia. A diaphragmatic elevation occurs with a reduction in static and dynamic pulmonary compliance $^{63,64}$. The increase in IAP also reduces functional residual capacity and residual volume ${ }^{16}$, leading to ventilation-perfusion abnormalities and hypoventilation, which results in hypoxia and hypercarbia ${ }^{65}$.

\section{DISCUSSION}

Critically ill postoperative patients are at high risk of development of IAH, and decompression should be considered with more frequency as the treatment of choice for patients with ACS, as we observed in our case reports. These patients should have frequent measurements of urinary bladder pressure. Recently, Ivy et al. ${ }^{66}$ reported that IAH also occurs commonly in major burn patients, and ACS is seen regularly in patients with burns on more than $70 \%$ of the body surface area.

In our patients, initial management through volume replacement and optimization of filling pressures generally was not sufficient to achieve satisfactory clinical compensation. ICU bedside abdominal surgery should be considered if the patient is too unstable for transport to the operation room and the surgeon believes a limited procedure, such as decompression of IAP, will be lifesaving ${ }^{67}$.

Although celiotomy results in immediate relief, it can be associated with exsanguination in emergency situations. Classical examples include hemoperitoneum from abdominal trauma and retroperitoneal hematoma from pelvic fracture. In the last case, early treatment must be focused on the stabilization of fracture and control of bleeding, because attempts to open the abdomen can lead to death. Therapy must be of support, dealing afterwards with the consequences of IAH.

We must not forget that closure of the abdomen after any procedure asso- 
ciated with profound hemorrhage and shock, massive volume resuscitation, and resultant visceral and retroperitoneal edema represents a balance between the IAP necessary to tamponade bleeding and the IAP that produces fulminant $\mathrm{ACS}^{60}$.

In severe abdominal trauma followed by hemorrhagic shock and vigorous fluid replacement in which development of IAH can be foreseen due to massive bowel, abdominal wall, retroperitoneum, and solid organ edema, cautious evaluation must be done at the time of primary abdominal closure $^{45}$. Tight abdominal closure under this situation can worsen the tissue injury, promote sepsis, cause necrotizing fasciitis, fascia dehiscence, and evisceration and can result in a fatal outcome ${ }^{68}$.

The most optimal management of the ACS is the open abdomen. It is the preferred prophylaxis before any evidence of clinical deterioration ${ }^{69,70}$.

The use of temporary abdominal content containment is advised. Since the use of absorbable prosthetic closure has been associated with very high rates of formation of fistula and ventral hernia, the use of nonabsorbable prosthetic abdominal closures, particularly with Gore-Tex, has proved efficacious in the prevention of postoperative ACS (only 1 of 18 closed in this manner developed ACS requiring reoperation). The use of nonabsorbable prosthetic abdominal closures enhances the possibility for delayed abdominal closure and minimizes the risk of gastrointestinal fistulization ${ }^{71}$. Ghimenton et $\mathrm{al}^{72}$ compared the use of plastic bags with polyglactin mesh, and they defend the use of the former, which are cheaper and are as effective as the other for temporary abdominal closure.

The silastic "Bogota" bag can be fashioned from a sterilized 3L Folley irrigation bag cut along its seams, fashioned to the necessary size, and sewn to the fascia with 0-monofilament suture or stapled to the skin ${ }^{60}$.

Standard towel clips are applied 1 to $2 \mathrm{~cm}$ from the skin edge and 1 to 2 $\mathrm{cm}$ apart for the entire length of the incision and then are wrapped in a moist towel and covered with a self-adhesive iodized plastic sheet. If excessive tension develops, successive removal of clips can reduce IAP ${ }^{60}$.

We must emphasize that all the individuals responsible for the care of patients in the ICU should be familiar with the concepts and techniques of open abdomen wound management ${ }^{67}$. For patients at risk we advocate the continuous measurement of urinary bladder pressure for early detection of ACS, in addition to using temporary abdominal content containment.
CLEVA R de e col. - Insuficiência renal aguda secundária à síndrome compartimental abdominal: relato de quatro casos e revisão da literatura. Rev. Hosp. Clín. Fac. Med. S. Paulo 56(4):123-130, 2001.

Descrevemos quatro casos de síndrome compartimental abdominal complicadas por insuficiência renal aguda e prontamente revertidas por diferentes métodos de descompressão abdominal.

Caso 1: paciente obesa de 57 anos no pós-operatório de correção de hérnia incisional gigante com pressão intra-abdominal de 24 mm Hg. Após sedação e curarização, a PIA caiu para $15 \mathrm{~mm} \mathrm{Hg}$. Caso 2: paciente de 73 anos com abdômem agudo inflamatório submetida à laparotomia exploradora quando foi diagnosticado pneumoperitôneo hipertensivo. Durante a cirurgia houve melhora da diurese. Caso 3: paciente de 18 anos submetido a hepactetomia apresentou coagulopatia e sangramento hepático necessitando tamponamento com compressas, evoluindo com oligúria e
PIA de 22 mm Hg. Na reoperação, após remoção das compressas houve melhora importante do fluxo urinário. Caso 4: paciente de 46 anos com cirrose hepática foi admitido após correção de hérnia incisional com pressão intra-abdominal de $16 \mathrm{~mm} \mathrm{Hg}$. Após paracentese, a pressão intra-abdominal caiu para 11 $\mathrm{mm} \mathrm{Hg}$.

DESCRITORES: Insuficiência renal aguda. Síndrome compartimental abdominal. 
1. WENDT EC - Uber den Einflus des intra-abdominellen Druckes auf dies Absonderungsgeschwindigkeit des Hames. Arch Heilkunde 1876;17:527.

2. MAYBERRY JC - Prevention of the abdominal compartment syndrome. Lancet 1999;354:1749-1750.

3. THORINGTON JM \& SCHMIDT CF - A study of urinary output and blood pressure changes resulting in experimental ascites. Am J Med Sci 1923;165:880-890.

4. BRADLEY SE \& BRADLEY GP - The effect of increased intraabdominal pressure on renal function in man. J Clin Invest 1947;26:1010-1022.

5. SCHEIN M, WITTMANN DH, APRAHAMIAN C et al. - The abdominal compartment syndrome. The physiological and clinical consequences of elevated intra-abdominal pressure. J Am Coll Surg 1995;180:745.

6. MELDRUM DR, MOORE FA, MOORE EE et al. - Prospective characterization and selective management of the abdominal compartment syndrome. Am J Surg 1997;174:667-672.

7. WILLIAMS M \& SIMMS HH - Abdominal compartment syndrome: case reports and implications for management in critically ill patients. Am Surg 1997;63(6):555-558.

8. KRON IL, HARMAN PK \& NOLAN AP - The measurement of intraabdominal pressure as a criterion for abdominal re-exploration. Ann Surg 1984;199:28.

9. BARNES GE, LAINE GA, GYAM PY et al. - Cardiovascular responses to elevation of intra-abdominal hydrostatic pressure. Am J Physiol 1985;248:R208-R213.

10. STONE HH \& FULENWIDER JT - Renal decapsulation (decaps) in the prevention of post-ischemic oliguria. Ann Surg 1977;186:343-355.

11. HARMANN PK, KRON IL, McLACHLAN HD et al. - Elevated intraabdominal pressure and renal function. Ann Surg 1982;196:594-597.

12. DIEBEL LN, DULCHAVSKY AS \& WILSON RF - Effects of increased intra-abdominal pressure on mesenteric arterial and intestinal mucosal blood flow. J Trauma 1992;33:45-49

13. LIOLIOS A, OROPELLO JM \& BENJAMIN E - Gastrointestinal complications in the Intensive Care Unit. Clin Chest Medicine 1999;20:329-345.

14. SUGRUE M, JONES F, LEE A et al. - Intra-abdominal pressure and gastric intramucosal pH: is there an association? World J Surg 1996;20:988-991

15. IVATURY RR, DIEBEL LN, PORTER JM et al. - Intra-abdominal hypertension and the abdominal compartment syndrome. Surg Clin North Am 1997:77:783-800.

16. MUTOH T, LAMM WJ \& EMBREE LJ - Abdominal distension alters regional pleural pressures and chest wall mechanics in pigs in vivo. J Appl Physiol 1991;70:2611-2618.

17. SUGERMAN HJ, BARON PL, FAIRMAN RP et al. - Hemodynamic dysfunction in obesity hypoventilation syndrome and the effects of treatment with surgically induced weight loss. Ann Surg 1988;207:604-608.
18. SUGERMAN HJ, WINDSOR A, BESSOS $\mathrm{M}$ et al. - Intra-abdominal pressure, sagittal abdominal diameter and obesity comorbidity. J Intern Med 1997;241:71-79

19. JACQUES T \& LEE R - Improvement of renal function after relief of raised intra-abdominal pressure due to traumatic retroperitoneal hematoma. Anaesth Intens Care 1988;16:478-482.

20. FIETSAM R, VILLALBA M, GLOVER JL et al. - Intra-abdominal compartment syndrome as a complication of ruptured abdominal aortic aneurysm repair. Am Surg 1989;55:396-402.

21. AKERS DL, FOWL RJ KEMPEZINSKI RF et al. - Temporary closure of the abdominal wall by the use of silicone rubber sheets after operative repair of ruptured abdominal aortic aneurysm. J Vasc Surg 1991;14:48-51.

22. PLATELL CF, HALL J, CLARK G et al. - Intra-abdominal pressure and renal function after surgery to the abdominal aorta. Aust NZ J Surg 1990;10:213-218

23. SHELLY MP, ROBINSON AA, HESFOLD JW et al. - Hemodynamic effects following surgical release of increased intra-abdominal pressure. Br J Anesth 1987;59:800-805.

24. MORRIS JA, EDDY VA, BLINMAN TA et al. - The staged celiotomy for trauma. Ann Surg 1993;217:576-585.

25. SMITH PC, TWEDELL JS \& BESSEY PQ - Alternative approaches to abdominal wound closure in severely injured patients with massive visceral edema. J Trauma 1992;32:16-20

26. SHARP KW \& LOCICIERO RJ - Abdominal packing for surgically uncontrollable hemorrhage. Ann Surg 1992;215:467-475.

27. CUE GI, CRYER HG, MILLER FB et al. - Packing and planned reexploration for hepatic and retroperitoneal hemorrhage: critical refinements of a useful technique. J Trauma 1990;30:1007-1013.

28. LUCA A, CIRERA I, GARCIA-PAGAN JC et al. - Hemodynamic effects of acute changes in intra-abdominal pressure in patients with cirrhosis. Gastroenterology 1993;104:222-227.

29. OFFENBARTL K \& BENGMARK S - Intra-abdominal infection and gut origin sepsis. World J Surg 1990;14:191-195.

30. CELORIA G, STEINGRUB J, DAWSON JA et al. - Oliguria from high intra-abdominal pressure secondary to ovarian mass. Crit Care Med 1987;15:78-79.

31. GREENHALGH DG \& WARDEN GD - The importance of intraabdominal pressure measurements in burned children. J Trauma 1994;36:685-690

32. SMITH JH, MERRELL RC \& FAFFIN TA - Reversal of postoperative anuria by decompressive celiotomy. Arch Inter Med 1985; $145: 553-554$

33. PIERRI A, LAMM WJ, CARRARO L et al. - Hemodynamic alterations during massive incisional hernioplasty. J Am Coll Surg 1995;181:299-302.

34. MUTOH T, LAMM WJ \& EMBREE LJ - Volume infusion produces abdominal distention, lung compression, and chest wall stiffening in pigs. J Appl Physiol 1992;72:575-582. 
35. DIEBEL L, SAXE J \& DULCHAVSKY S - Effect of intra-abdominal pressure on abdominal wall flow. Am Surg 1992;58:573-576.

36. LACEY SR, BRUCE J \& BROOKS SP - The relative merits of various methods of indirect measurements of intra-abdominal pressure as guide to closure of abdominal wall defects. J Pediatr Surg 1987;22:1207-1211

37. IBERTI TJ, KELLY KM, GENTILI DR et al. - A simple technique to accurately determine intra-abdominal pressure. Crit Care Med 1987;15:1140.

38. RIDINGS PC, BLOCHER CR \& SUGERMAN HJ - Cardiopulmonary effects of raised intra-abdominal pressure before and after intravascular volume expansion. J Trauma 1995;39:1071-1075.

39. KIRKPATRICK AW, BRENEMAN FD, MCLEAN RF et al. - Is clinical examination an accurate indicator of raised intra-abdominal pressure in critically injured patients? Can J Surg 2000;43:207-211.

40. SUGRUE M, BUIST MD, LEE A et al. - Intra-abdominal pressure measurement using a modified nasogastric tube: description and validation of a new technique. Intensive Care Med 1994;20:588590 .

41.SHAFIK A, EL-SHARKAWY A \& SHARAF WM - Direct Measurement of Intra- abdominal Pressure in Various Conditions. Eur J Surg 1997;163:883-887.

42. GRIMES OF - Esophagus and diaphragm. In: DUMPHY JE \& WAY LW - Current surgical diagnosis and treatment. $2^{\text {nd }}$ ed. Los Altos, Lange Medical Pub, 1975. p.409-412.

43. COLLE GG, LOMAX DM, FERGUSON C et al. - Bedside measurement of intra-abdominal pressure (IAP) via indwelling naso-gastric tube: clinical validation of the technique. Intensive Care Med 1993;19:478-480.

44. CULLEN DJ, COYLE JP, TEPLICK R et al. - Cardiovascular, pulmonary, and renal effects of massively increased intra-abdominal pressure in critically ill patients. Crit Care Med 1989;17:118-121.

45. SHENASKY JH \& GILLENWATER JY - The renal hemodynamic and functional effects of external counterpressure. Surg Gynecol Obstet 1972;134:253-258.

46. KIRSCH AJ, HENSLE TW, CHANG DT et al. - Renal effects of $\mathrm{CO}_{2}$ insufflation: oliguria and acute renal dysfunction in a rat pneumoperitoneum model. Urology 1994;43:453-459

47. MC DOUGALL EM, MONK TG, WOLF JS et al. - The effect of prolonged pneumoperitoneum on renal function in an animal model. J Am Coll Surg 1996;182:317-328.

48. WITTMANN R \& DIETMAR H - Compartment Syndrome of the Abdominal Cavity. In: RIPPE G - Intensive Care Medicine. $4^{\text {th }}$ ed. New York, Lippincott, 1996. p.1888-1904.

49. CHIU AW, CHANG LS, BIRKETT DH et al. - The impact of pneumoperitoneum, pneumoretroperitoneum and gasless laparoscopy on the systemic and renal hemodynamics. J Am Coll Surg 1995;181:397-406.

50. VARGAS JC, FIELDS D, RAZVI H et al. - Direct renal parenchymal compression to $15 \mathrm{~mm} \mathrm{Hg}$ produce oliguria. J Urol 1995;153:514A.

51. ROITH DL, NYSKA M \& GLICK SM - The effect of abdominal pressure on plasma antidiuretic hormone levels in the dog. J Surg Res 1982;32:65-68.
52. KASHTAN J, GREEN JF, PARSONS EQ et al. - Hemodynamic effects of increased abdominal pressure. J Surg Res 1981;30:249-255.

53. ROBOTHAM JL, WISE RA \& BOMBERGER-BARNEA B - Effects of changes in abdominal on left ventricular performance and regional blood flow. Crit Care Med 1985;12:803-808

54. DIAMANT M, BENUMOF JL \& SAIDMAN LJ - Hemodynamics of intra-abdominal pressure. Anesthesiology 1978;48:23-27

55. KELMAN GR, SWAPP GH, SMITH I et al. - Cardiac output and arterial blood gas tension during laparoscopy. Br J Anaesth 1972;44:11551161.

56. BOYNTON BR, BARNAS GM, DADMUN JT et al. - Mechanical coupling of the rib cage, abdomen, and diaphragm through their area of apposition. J Appl Physiol 1991;70:1235-1240.

57. RASMUSSEN IB, BERGGREN U, ARVIDSON D et al. - Effects of pneumoperitoneum on splanchnic hemodynamics: an experimental study in pigs. Eur J Surg 1995;161:819-824.

58. BOMGARD F, PIANIM N, DUBECZ $S$ et al. - Adverse consequences of increased intra-abdominal pressure on bowel tissue oxygenation. J Trauma 1995;39:519-524.

59. ELEFTHERIADIS E, KOTZAMPASSI K, PAPANOTAS K, et al. Gut ischemia, oxidative stress, and bacterial translocation in elevated abdominal pressure in rats. World J Surg 1996;20:11-15

60. SAGGI BH, SUGERMAN HJ, IVATURY RR et al. - Abdominal compartment syndrome. J Trauma 1998;45:597-609.

61. PUSAJO JF, BUMASCHNY E, AGURROLA A et al. - Postoperative intra-abdominal pressure: its relation to splanchnic perfusion, sepsis, multiple organ failure and surgical re-intervention. Int Crit Care Dig 1994;13:2-8.

62. PAUL A, TROIDL H, PETERS S et al. - Fatal intestinal ischemia following laparoscopic cholecystectomy. Br J Surg 1994;81:12071211.

63. IVANKOVICH A, MILETICH D, ALBRECHT R et al. - Cardiovascular effects of intraperitoneal insufflation with carbon dioxide and nitrous oxide in the dog. Anesthesiology 1975;42:281-287.

64. OBEID F, SABA A, FATH $J$ et al. - Increases in intra-abdominal pressure affect pulmonary compliance. Arch Surg 1995;130:544548.

65. MOTEV M, IVANKOVICH A, BIENIARZ J et al. - Cardiovascular effects and acid-base and blood gas changes during laparoscopy. Am J Obstet Gynecol 1973;115: 1002-1012.

66.IVY ME, ATWEH NA, PALMER J et al. - Intra-abdominal hypertension and abdominal compartment syndrome in burn patients. J Trauma 2000;49:387-391.

67. MAYBERRY JC - Bedside open abdominal surgery. Utility and wound management. Crit Care Clin 2000;16;151-172.

68.CHANG M, MILLER PR, D'AGOSTINO R et al. - Effects of abdominal decompression on cardiopulmonary function and visceral perfusion in patients with intra-abdominal hypertension. J Trauma 1998;44:440-445.

69. BRITT L - Surveyed opinion of American trauma surgeons on the prevention of the abdominal compartment syndrome (Editorial). J Trauma 1999;47:513. 
70. SAXE JM, LEDGEWOOD AM \& LUCAS CE - Management of the difficult abdominal closure. Surg Clin North Am 1993;73(2):243251.

71. CIRESI DL, CALI RF \& SENAGORE AJ - Abdominal closure using nonabsorbable mesh after massive resuscitation prevents abdominal compartment syndrome and gastrointestinal fistula. Am Surg 1999;65:720-725.
72. GHIMENTON F, THOMSON SR, MUCKART DJ et al. - Abdominal content containment: practicalities and outcome. Br J Surg 2000;87:106-109.

Received for publication on March 20, 2001. 